\title{
Electrical Trees in a Composite Insulating System Consisted of Epoxy Resin and Mica: The Case of Multiple Mica Sheets for Machine Insulation
}

\author{
V. A. Kioussis \\ Department of \\ Electrical \& Computer \\ Engineering, \\ Democritus University \\ of Thrace, Greece
}

\author{
M. G. Danikas \\ Department of \\ Electrical \& Computer \\ Engineering, \\ Democritus University \\ of Thrace, Greece
}

\author{
D. D. Christantoni \\ Department of \\ Electrical \& Computer \\ Engineering, \\ Democritus University \\ of Thrace, Greece
}

\author{
G. E. Vardakis \\ Department of \\ Electrical \& Computer \\ Engineering, \\ Democritus University \\ of Thrace, Greece
}

\author{
A. Bairaktari \\ Department of \\ Electrical \& Computer \\ Engineering, \\ Democritus University \\ of Thrace, Greece
}

\begin{abstract}
Epoxy resin and mica sheets consist the essential insulation of rotating machine stator bars. Such an insulation, although very resistant to partial discharges, is subjected to considerable electrical stresses and consequently electrical trees may ensue. In this paper, an effort is made to simulate electrical tree propagation in multiple epoxy resin/mica sheets with the aid of Cellular Automata (CA). An attempt to compare the simulation results with experimental results is also made.
\end{abstract}

Keywords-:electrical trees; composite insulation; dielectric strength; breakdown; mica sheets; epoxy resin; machine insulation

\section{INTRODUCTION}

Electrical trees constitute a network of channels full of either solid, gaseous or even liquid byproducts. Electrical trees emanate either from sharp electrodes or from enclosed cavities or from other enclosed foreign particles in the insulation. They seem to come from partial discharge (PD) activity and/or local breakdowns of the insulating material. Electrical trees can be of branch-type or of bush-type. Propagation of electrical trees has as a consequence the total breakdown of the insulation. Electrical tress are due mainly to electric field intensifications $[1,2]$, but they depend also on the experimental (or service) conditions, i.e., among others, on the insulating material itself, the level of the applied voltage, the type of the applied voltage, the frequency, the inclusion of foreign particles, the humidity and the temperature [3]. For the creation of electrical trees, first of all there must be an injection of charges from the electrodes and/or from a foreign particle or cavity, then a propagation of small channels of diameter smaller than $10 \mu \mathrm{m}$ in the insulation. The final stage is when the initial channels touch the opposite electrode and the channels acquire a larger diameter because of the PD inside them. During the final stage, the channels seem to be pipe-shaped channels. When the diameter of such channels acquires a critical value, the final breakdown ensues. Such channels are characterized from diameter values between $10 \mu \mathrm{m}$ and $150 \mu \mathrm{m}$ [4].

Rotating machines' insulation consists of sheets of mica in epoxy resin. It is a good insulating system, resistant to PD.
Previous research indicated that the mica sheets elongate the treeing path and at the same time delays the time to total collapse [5]. In the context of the present paper, simulations of the growth of electrical trees are attempted in an epoxy resin/mica system with multiple mica sheets. A discussion follows as to whether such a system can withstand eventual breakdown.

\section{THE BARRIER EFFECT IN THE CASE OF ROTATING MACHINE INSULATION}

The elongation of electrical tree paths and the deceleration of electrical tree growth have recently been experimentally studied. The mica sheet acts as a barrier and hinders the electrical tree growth. The longer the mica sheet, the more the time to breakdown. It was shown that electrical trees cannot penetrate the mica barriers and try to go around them, increasing thus the time to ultimate failure [6]. The mica sheets are influenced, among other factors, from mechanical stress and the space charges [7]. The number of mica sheets plays also a significant role in hindering the propagation of electrical trees in a composite insulation. Electrical trees usually develop across the interfacial region between mica and epoxy resin or in overlapped areas [8]. The speed at which an electrical tree propagates across an interfacial region is defined from the chemical bonding between the mica sheets and epoxy resin. The mica sheet insertion affects the mechanical properties of the composite material. A decrease in tensile strength, modulus of elasticity and fracture roughness as a result of plasticization is mirrored in the decreased resistance of the material to electrical treeing growth [9]. The time to inception of electrical treeing is smaller in insulating systems which have internal mechanical stresses than in systems which are mechanical stress-free. Important is the role of the bonding between mica sheet and epoxy resin [10]. The interfacial region between mica barrier and epoxy resin is affected by the temperature. Electrical trees seem to acquire more pointed characteristics when the temperature rises, whereas they tend to be more spread out in lower temperatures. Humidity plays also a role by affecting the internal mechanical stresses [11]. 
In an ideal situation the mica sheets should be smooth but in practical conditions mica sheets may be deformed and, consequently, non-uniform electric field distributions may result. This in turn may give rise to partial discharges and the creation of electrical trees [12].

\section{SiMULATION MODELS OF ELECTRICAL TREES}

Various models on the simulation of electrical trees have been proposed, such as the NPW model, based on the addition of a new branch or a new bond in the "lattice" according to a probabilistic approach [13, 14]. In another effort, it was considered that the local value of the damage/unit length had to be greater than a critical value $\mathrm{W}_{\mathrm{c}}$. and the electric field value near the damaged area had to be greater than the critical dielectric strength of the material $[15,16]$. In cases, where treeing is studied with the presence of a barrier, the phenomenon propagates through the weaker medium and not through the barriers. Further, in another approach employing a non-uniform electrode arrangement, it was shown that treeing depends on the electric field intensity as well as on the presence of space charges [17].

\section{CEllular AUtOMATA SIMUlation METHOD}

Cellular Automata (CA) are used in the present paper for the simulation of the electrical tree propagation. In this model, the algorithm takes into account the variation of the dielectric constant of epoxy resin. The simulation of electrical tree propagation using Cellular Automata as a simulation method, has already been presented elsewhere $[18,19]$. In the present paper a combination of two insulating materials is used (epoxy resin and mica sheet).

The simulation method based on CA takes into account the fluctuations of permittivity, the local dielectric strength of the materials and the boundary conditions according to the electromagnetic theory at the interfaces between:

- $\quad$ epoxy resin and mica sheet

- $\quad$ epoxy resin and electrodes

The simulation successfully reproduces electrical tree propagation with a point-plane electrode arrangement. Moreover, it simulates conditions where homo and heterocharges are present $[20,21]$. It also successfully reproduces tree formation in the presence of voids, conducting and nonconducting inclusions $[22,23]$. Time and space, according to $\mathrm{CA}$, are discrete physical quantities and any physical system can be divided into a number of cells. Every cell is defined by a number of parameters defining the internal state of the cell. A common rule for all cells is applied, determining the evolution of the phenomenon $[24,25]$. The point that differentiates this geometry is applied to an epoxy resin sample and the electrical tree propagation is shown in two cases.

In this paper, the electric field calculation is obtained with the aid of the Partial Differential Equation Toolbox (PDE) of MATLAB. In the Graphical User Interface (GUI) of PDE, the suitable geometry for the electrical tree growth is chosen. The point electrode and the opposite plane electrode are placed between epoxy resin and more mica barriers. After the geometry construction, the boundary conditions between the interfaces of the materials are defined. The PDE creates a mesh of nodes in the region of interest, according to the Finite Element Method (FEM). The potential distribution is calculated with the aid of Laplace's equation:

$$
\nabla^{2} \mathrm{~V}=0
$$

According to $\mathrm{CA}$, the insulating system is divided in a

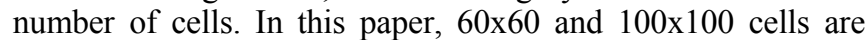
chosen to simulate the electrical tree propagation. The electrical field is calculated with the aid of:

$$
\mathrm{E}=-\partial \mathrm{V} / \partial \mathbf{x}
$$

The above equation, for the purposes of this simulation, is modified to:

$$
|\mathrm{E}| \approx \mathrm{g}|\mathrm{VA}-\mathrm{VB}| / \mathrm{x}
$$

The dielectric inhomogeneity factor $g$ takes values between 0.9 and 1.1. This factor is dimensionless and is created randomly corresponding to each cell through the appropriate matrix $(60 \times 60,100 \times 100)$. The above mentioned factor absorbs the fluctuations of the dielectric environment surrounding each cell, creating a variation in the electrical field strength calculated with the aid of Cellular Automata. This factor contributes to the notion of the internal state of the cell since it is used in the calculations of the electrical field for every cell separately [26].

The cells belonging to the physical insulating system are divided into five categories:

- the cells belonging to the point electrode

- the cells belonging to the plane electrode

- the cells belonging to the electrical tree

- the cells belonging to the main insulating material (epoxy resin)

- $\quad$ the cells belonging to the second insulating material (mica sheets-mica volume).

\section{THEORETICAL CALCULATIONS}

The electric field is calculated with the aid of (3), for every cell separately, towards all directions. The algorithm compares each value with the local dielectric strength of the insulating material. This happens according to the CA rule for the evolution of the physical system. It is assumed that interactions are local. If the calculated electric field is larger than the local dielectric strength, then the algorithm converts the cell belonging to the insulating material into a cell of the treeing structure. When the algorithm checks each cell, a new geometry emerges with the addition of the new treeing cells. The boundary conditions are defined again and the process is repeated until the electrical tree finalizes its path. Our initial assumption is that the field value at the tip of the upper needle electrode is almost equal to the dielectric strength of the insulating material. This helps the creation of the treeing 
structure from the needle electrode and the further study of the propagation of the tree.

The tree may finalize its path on the following cases: a) if the tree reaches the opposite electrode, b) if the calculated electric field is smaller than the local dielectric strength of the insulating material.

For the tree propagation study in a system of parallel sheets of mica and of epoxy resin, the system was simulated with the aid of MATLAB. An electrode system of needle-plane was used and a positive voltage was applied to the needle upper electrode. The plane electrode was at zero voltage. The whole procedure followed the steps:

- creation of the electrode arrangement via the Partial Differential Equation TOOLBOX (PDE Toolbox)

- application of the potential values at the interfaces of the two materials as well as at the boundaries

- creation of the necessary tables, one for the random fluctuation due to the dielectric environment, the other for the processing of the potential values

- calculation of the electric field with the aid of Laplace's equation,

- $\quad$ finding the places which are probable sources of treeing,

- creation of a code with which each tree cell is controlled w.r.t. its five neighboring cells (this is obtained with a comparison of the electric field of each cell with the dielectric strength. If its value is larger than the dielectric strength, then the cell is already a cell of the tree) and

- repetition of the whole procedure, i.e. the cells which came about from the above procedure are part of the treeing structure and the whole process is repeated in order to find new cells (it goes without saying that the values of the electric field are calculated again because of the changed new structure, which resulted from the propagation of the tree).

The samples were constructed symmetrically (nxn) and the needle was put in the middle of the upper surface and in contact with the epoxy resin. The rest of the space between the needle and the earthed plane electrode was divided into sheets of epoxy resin and mica, so that all sheets to have the same thickness. The dielectric constants of epoxy resin were taken to be 4 and of mica 6 . It is assumed that there are no space charges distributed inside the solid insulating material so the space charge density is equal to zero $(\rho=0)$ and therefore Laplace's equation is solved for the potential distribution. The applied potential at the upper electrode is 28000 Volts and 0 Volts at the opposite plane electrode.

It should be noted that for the calculation of the electric field between the two electrodes, the Finite Element Method (FEM) was used. As far as the boundaries of the sample and the air, the boundary conditions of von Neumann were applied:

$$
\mathrm{E} \operatorname{grad}(\mathrm{V})+\mathrm{q} \mathrm{V}=\mathrm{g}
$$

where $\mathrm{V}$ is the potential (Volt), $\mathrm{g}$ is the surface charge and $\mathrm{q}$ is a parameter defined on the interface. It was taken that $\mathrm{q}=0$ and $\mathrm{g}=0$, in order to avoid the generalized form of von Neumann's conditions.

For the interfaces between epoxy resin and mica, Dirichlet conditions were assumed, i.e.:

$$
\mathrm{h}=\mathrm{Vr}
$$

where $r$ is the value of potential at the tip of the needle electrode. For the simulations presented, mixed boundary conditions of both types (Neumanns' and Dirichlets') are applied to the interfaces. The consecutive layers of epoxy resin and mica affect the potential distribution and therefore the resultant electric field inside the component dielectric. The potential values and the surface values applied to each interface between the materials are defined with the aid of the dielectric constants of mica and epoxy resin. The aforementioned values are also affected by the distance between the tip of the needle and the opposite plane electrode.

The electrical tree propagation is a dynamical phenomenon where the potential at the tip of the tree is considered to be equal to the needle electrode potential so, as a consequence, no voltage drop appears along the electrical tree path. During the tree propagation, the graphical geometry alters so new values for boundary conditions of both types (potential values and surface charge values) are applied to the interfaces between the materials consisting the insulating system.

Electric fields develop in all regions of the composite insulating system. Beginning from the plane electrode, the first electric field appears in epoxy resin between the plane earthed electrode and the first interface between the epoxy resin and the mica sheet. The second electric field appears inside the first mica sheet. Inside the consecutive layers of mica and epoxy resin appear the respective electric fields which are homogeneous inside each layer due to the parallel interfaces between mica and epoxy resin.

The following equation determines the potential distribution across the first interface between epoxy resin and mica:

$$
\mathrm{V}(\mathrm{r})=\mathrm{C}_{1} \ln \mathrm{r}+\mathrm{C}_{2}
$$

where $r$ is the distance between the cell and the grounded opposite plane electrode and:

$$
\mathrm{V}(\mathrm{r})=\mathrm{C} 3 \ln \mathrm{r}+\mathrm{C} 4
$$

defines the potential distribution across the second interface of mica and epoxy resin. The methodology that is followed for the definition of the potential at the interfaces between the consecutive layers of mica and epoxy resin is in agreement with the electromagnetic theory analysis where in twodimensional geometries, such as it is studied in the present paper, the variable $r$ which is the one-dimensional distance from the plane electrode is the appropriate variable for potential distribution and description because the resultant electric fields inside the layers are homogeneous. In such cases a one-dimensional variable (distance $r$ ) defines uniquely the 
equipotential lines which are parallel to the interfaces without any need for a second variable.

Considering $\mathrm{d}_{1}$ the distance between the plane electrode and the first interface, $d_{2}$ the distance between the plane electrode and the second interface and following with the same analysis, $\mathrm{d}_{\mathrm{i}}$ the distance between the plane electrode and the i-th interface, there is a need, according to the electromagnetic theory, that (6) and (7) must be satisfied at the common surfaces (interfaces). For the first interface from the plane electrode the variable $\mathrm{r}=\mathrm{d}_{1}$ :

$$
\mathrm{C} 1 \ln (\mathrm{d} 1)+\mathrm{C} 2=\mathrm{C} 3 \ln (\mathrm{d} 1)+\mathrm{C} 4
$$
to:

The continuity of the vertical vectors of electric field results

$$
[\mathrm{C} 1 \ln (\mathrm{d} 1)] /[\mathrm{C} 3 \ln (\mathrm{d} 1)]=\varepsilon 2 / \varepsilon 1
$$

where $\varepsilon_{2}=4$ (epoxy resin) and $\varepsilon_{1}=6$ (mica). The same procedure is followed for all interfaces and it is evident that it can be implemented also for the i-th interface between epoxy resin and mica sheet with a distance $d_{i}$ from the plane electrode:

$$
\mathrm{C} 1 \ln (\mathrm{di})+\mathrm{C} 2=\mathrm{C} 3 \ln (\mathrm{di})+\mathrm{C} 4
$$
to:

The continuity of the vertical vectors of electric field results

$$
[\mathrm{C} 1 \ln (\mathrm{di})] /[\mathrm{C} 3 \ln (\mathrm{di})]=\varepsilon 2 / \varepsilon 1
$$

Figure 1 shows the distribution of the equipotential lines from the upper needle electrode down to the plane electrode.
There are two mica sheets inside the main insulating material which is considered to be epoxy resin. It is obvious that there are five electric fields, i.e.

- $\quad$ an electric field between the tip of the needle electrode and the first mica sheet

- another one between the earthed plane electrode and the last mica sheet

- $\quad$ another one between the mica sheets and

- two electric fields inside the mica sheets.

\section{Simulation RESUlts}

Simulation of a cell arrangement of 100x100 cells implies that the dimensions of each cell are $1 \times 1 \mathrm{~mm}$ and the dimensions of the sample are $100 \times 100 \mathrm{~mm}$. Three different voltages were applied at the point electrode, namely $35 \mathrm{kV}, 28$ $\mathrm{kV}$ and $27 \mathrm{kV}$. The critical strength was taken to be $26 \mathrm{kV} / \mathrm{mm}$ for epoxy resin and $35 \mathrm{kV} / \mathrm{mm}$ for the mica sheets (in all simulations the aforementioned dielectric strengths for epoxy resin and mica were kept the same for the sake of comparison).

With $27 \mathrm{kV}$, treeing has a bushy form and its propagation is quasi-symmetric (Figure 2), whereas with $28 \mathrm{kV}$ treeing takes the form of a more pointed type (Figure 3 ). It seems that in this case, the branches develop independently from each other. In Figure 4, a voltage of $40 \mathrm{kV}$ is applied. In contradistinction to the two previous cases, a voltage of $40 \mathrm{kV}$ creates trees that penetrate the first mica sheet.

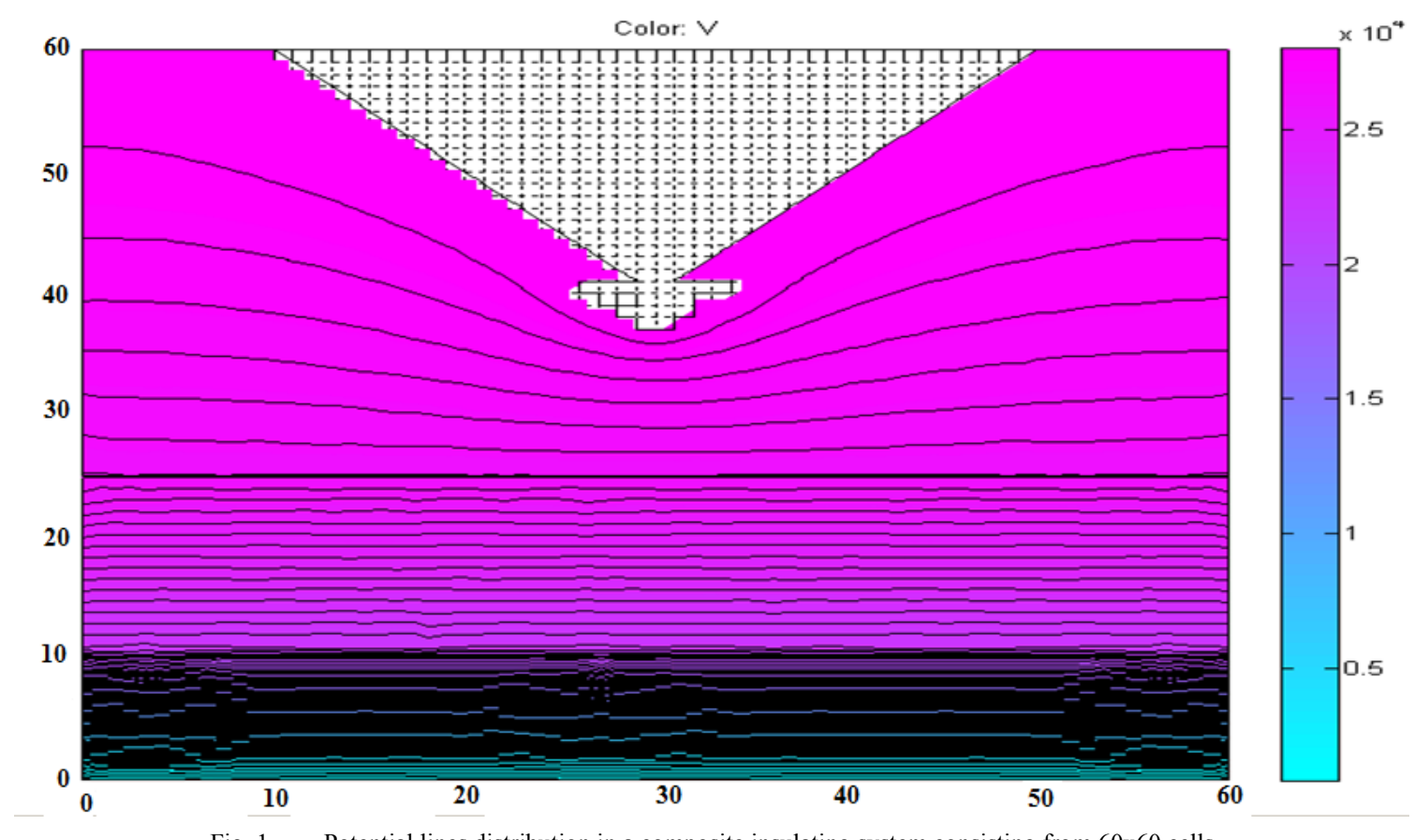

Fig. 1. Potential lines distribution in a composite insulating system consisting from $60 x 60$ cells 


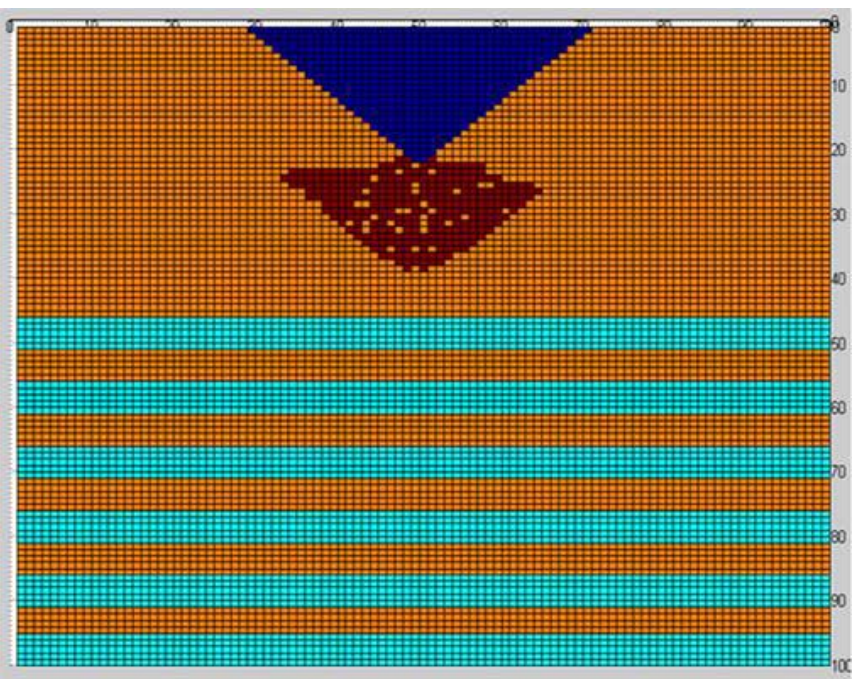

Fig. 2. Tree propagation for an applied voltage of $27 \mathrm{kV}$ and a dielectric strength of $26 \mathrm{kV} / \mathrm{mm}$ (six mica sheets).

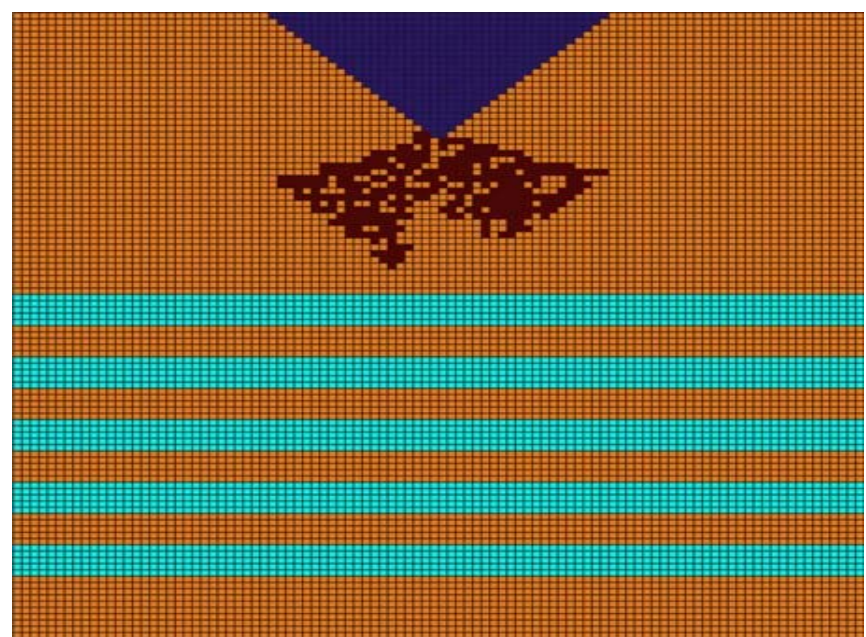

Fig. 3. Tree propagation for an applied voltage of $28 \mathrm{kV}$ and dielectric strength of $26 \mathrm{kV} / \mathrm{mm}$ (five mica sheets).

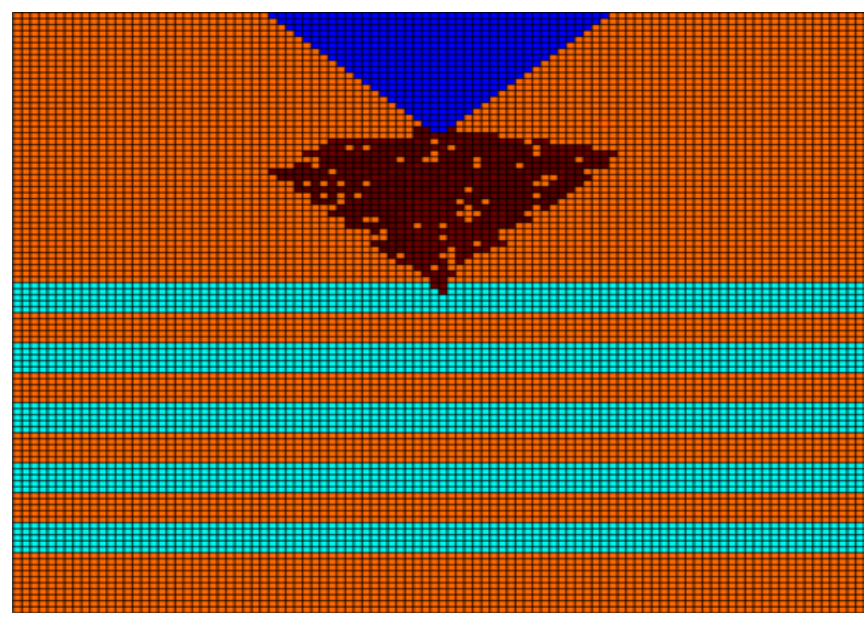

Fig. 4. Tree propagation for an applied voltage of $35 \mathrm{kV}$ and a dielectric strength of $26 \mathrm{kV} / \mathrm{mm}$ (five mica sheets).

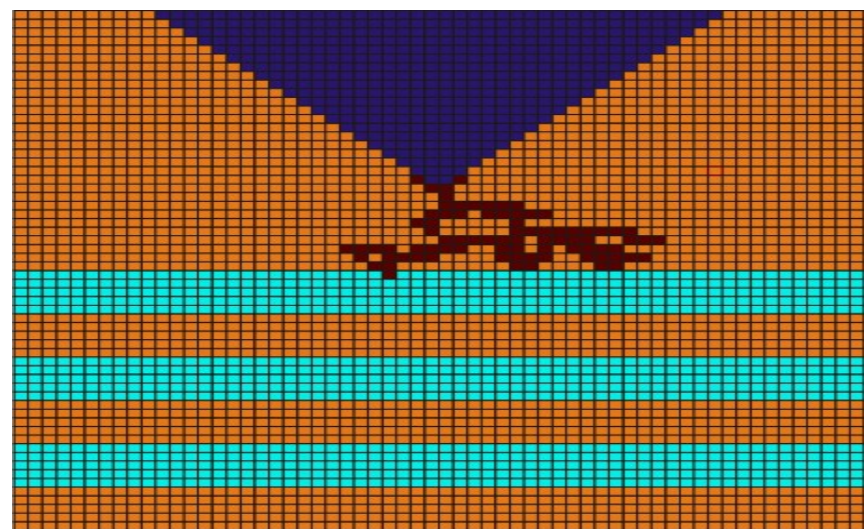

Fig. 5. Tree propagation for an applied voltage of $27 \mathrm{kV}$ and dielectric strength of mica $35 \mathrm{kV} / \mathrm{mm}$ (three mica sheets).

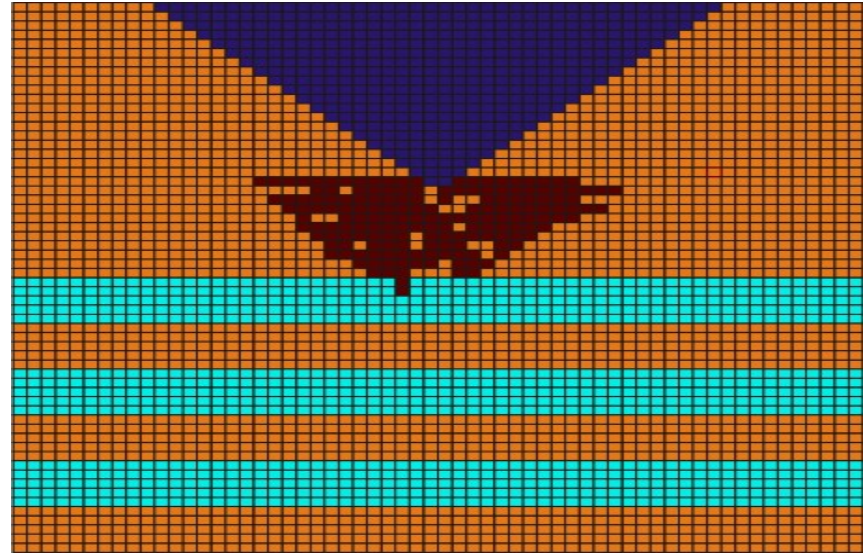

Fig. 6. Tree propagation for an applied voltage of $28 \mathrm{kV}$ and dielectric strength of mica $35 \mathrm{kV} / \mathrm{mm}$ (three mica sheets).

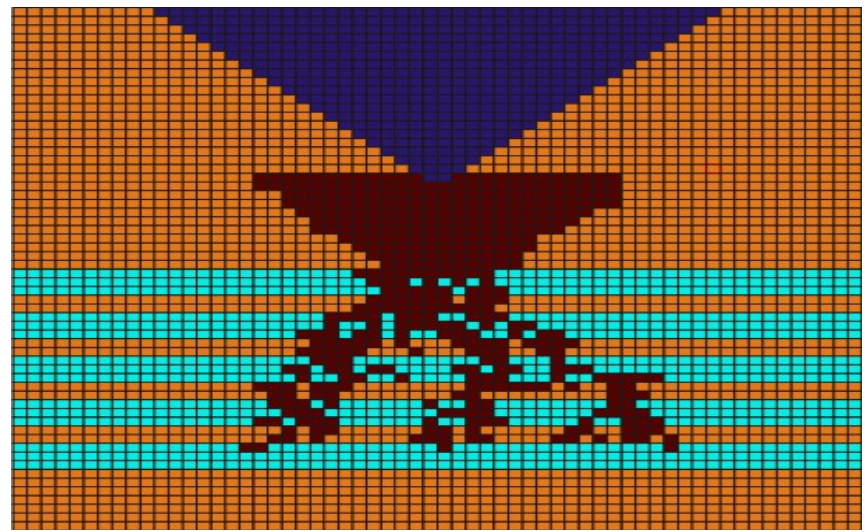

Fig. 7. Tree propagation for an applied voltage of $36 \mathrm{kV}$ and dielectric strength of epoxy resin $26 \mathrm{kV} / \mathrm{mm}$ (five mica sheets).

In a cell arrangement of $60 \times 60$ cells, the mica sheets as well as the epoxy resin have the same thicknesses as in the case of $100 \times 100$ cells. For voltages of $27 \mathrm{kV}$ and $28 \mathrm{kV}$, the tree can only slightly penetrate the first mica sheet (Figures 5 and 6), whereas with voltages of $36 \mathrm{kV}$ and $37 \mathrm{kV}$ (Figures 7 and 8), there is a significant penetration of the sheets down to the earthed electrode. The dielectric strength of epoxy resin was taken to be $26 \mathrm{kV} / \mathrm{mm}$ and for the mica sheets $35 \mathrm{kV} / \mathrm{mm}$. 


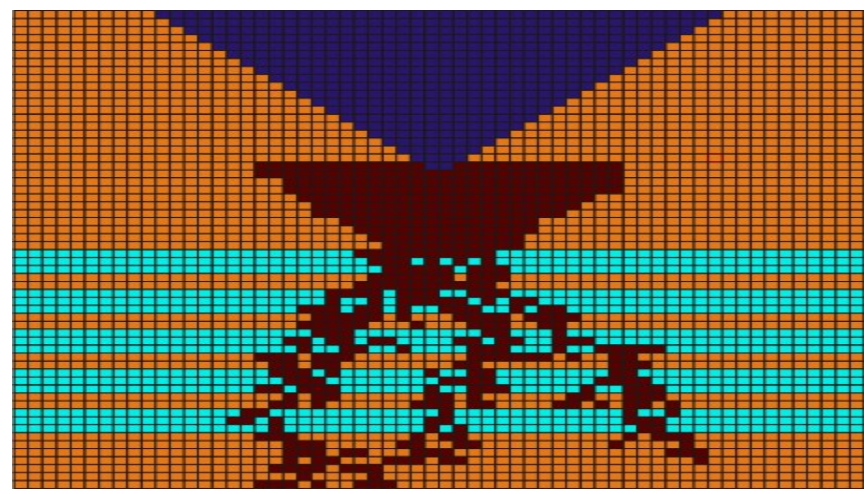

Fig. 8. Tree propagation for an applied voltage of $37 \mathrm{kV}$ and dielectric strength of epoxy resin $26 \mathrm{kV} / \mathrm{mm}$ (five mica sheets).

It seems that mica sheets act as barriers to the tree propagation, hindering thus the ultimate failure of the whole system. The calculation of the electric field at each step and every point of the insulating system was accurate since with the aid of the PDE Toolbox the Laplace's equation is solved and the potential distribution is computed. Particular attention should be paid to the factor g, which incorporates parameters such as the different dielectric environment and the existence of microcavities. Generally speaking, the mica sheets hinder tree propagation and only when the electric field is too large, penetration occurs through the entire insulting system.

Comparison of the present simulation results with experimental data indicates that our method can simulate the reality of breakdown in complex machine insulating systems. Experimental data have shown that treeing creates conducting paths, which in turn may be transformed into breakdown channels leading to total breakdown [27].

It seems from the above that the penetration of mica sheets depends on the local variation of the dielectric constant, on the applied voltage at the tip of the upper electrode and on the local breakdown strength of the insulating system.

\section{DISCUSSION}

It is evident from the results that variations of the electric field produced by the factor $\mathrm{g}$, influences the electrical tree propagation. Such local variations of $g$ contribute into the propagation of electrical trees [26].

In all simulations the mica sheet is considered to have a comparable thickness w.r.t. the sheets of epoxy resin. For the arrangement of $60 \times 60$ cells the sheets have the same thickness. For applied voltage of $27 \mathrm{kV}$ and $28 \mathrm{kV}$, the treeing propagation cannot continue inside the mica sheets. On the contrary with $36 \mathrm{kV}$, the tree breaks down some mica sheets without penetrating through all of them. Only with $37 \mathrm{kV}$ there is a total breakdown of the whole insulating system. It is to be noted that in the first mica sheet, treeing is somehow of bushtype whereas -as the penetration continues- treeing has somehow a more pointed form. This can be explained by the fact that the dielectric constant and the dielectric strength of the mica sheets have higher values than those of the surrounding epoxy resin.
It was noticed that with a higher applied voltage $(28 \mathrm{kV})$, the tree presents a more pointed form. In other cases, with even higher applied voltages ( $37 \mathrm{kV}$ and $38 \mathrm{kV})$, the treeing form starts as bushy to continue as more pointed. Generally, the higher the applied voltage the more dense is the type of the tree.

The above are in agreement with [10]. The applied voltage influences the shape and form of the tree in the material, as shown before [28]. Although the sequence of events is not as simple as described in the present paper, we believe that the described above simulation method gives a reasonable insight as to the workings of machine insulation degradation. What was described before, it is not in disagreement with experimental data such as those presented in [29], where partial discharge activity and delamination are intimately linked and organic components (such as epoxy resin) degrade.

The present work also somehow completes work done before [5], where it was also shown that mica sheets act as barriers hindering the propagation of electrical trees. In that case, however, only a limited number of mica sheets were used, whereas in the present paper a more or less full system of epoxy resin/mica sheets was investigated. In both papers the general conclusion is that mica sheets hinder the trees and the eventual breakdown.

A last remark should be made: in all above simulations the dielectric strength was taken to be higher than that of the epoxy resin but much lower than the mica dielectric strength mentioned in textbooks [30]. We think that this assumption is thoroughly justified since values of $700 \mathrm{kV} / \mathrm{mm}$ (for phlogopite mica) and of $1000 \mathrm{kV} / \mathrm{mm}$ for muscovite mica (as mentioned in [30]) are obtained with small samples in laboratory conditions but are not realizable in actual industrial service conditions.

\section{VIII.CONCLUSIONS}

In this work, electrical treeing simulations were obtained under various voltages in a multi-mica sheet system surrounded by epoxy resin. The simulations were performed with a nonuniform electrode arrangement. Trees appear and propagate and depending on the applied voltage, they reach the opposite electrode. The present simulations indicate that mica sheets act as barriers to the propagation of electrical trees. The present paper confirms previous simulation results and is in accordance with experimental data.

\section{REFERENCES}

[1] D. Kind, H. Kaerner, High-voltage insulation technology, Eds. Vieweg \& Sohn, Braunschweig, Germany, 1985

[2] E. Kuffel, W. S. Zaengl, J. Kuffel, High voltage engineering: fundamentals, $2^{\text {nd }}$ edition, Eds. Newnes, Oxford, England, 2000

[3] T. Tanaka, A. Greenwood, Advanced power cable technology, Vol. I, Eds. CRC Press, Boca raton, Florida, USA, 1983.

[4] R. Vogelsang, T. Farr, K. Froehlich, "The effect of barriers on electrical tree propagation in composite insulation materials", IEEE Transactions on Dielectrics and Electrical Insulation, Vol. 13, No. 1, pp. 373-382, 2006

[5] D. D. Christantoni, M. G. Danikas, G. E. Vardakis, A. T. Lekou, "Simulation of electrical tree growth in a composite insulating system 
consisted from epoxy resin and mica sheets", International Review on Modelling and Simulation, Vol. 3, No. 2, pp. 241-249, 2010

[6] T. Farr, R. Vogelsang, K. Froehlich, "A new deterministic model for tree in polymers with barriers", Annual Report of Conference on Electrical Insulation and Dielectric Phenomena (CEIDP), Kitchener, Ontario, Canada, pp. 673-676, October, 2001

[7] O. S. Gefle, S. M. Lebedev, V. Ya. Ushakov, "The mechanism of the barrier effect in solid dielectrics", Journal of Physics D: Applied Physics, Vol. 30, pp. 3267-3273, 1997

[8] R. Vogelsang, T. Farr, K. Froehlich, "Electrical tree propagation along barrier interfaces in epoxy resin", Annual Report Conference on Electrical Insulation and Dielectric Phenomena (CEIDP), Cancun, Mexico, pp. 946-950, October, 2002

[9] B. R. Varlow, G. J. Malkin, "Electrical treeing in mechanically prestressed insulation", IEEE Transactions on Dielectrics and Electrical Insulation, Vol. 7, No. 6, pp. 721-724, 2000

[10] R. Vogelsang, R. Brutsch, K. Froehlich, "The effect of tape overlappings in winding insulations on tree growth and breakdown time", Annual Report Conference on Electrical Insulation and Dielectric Phenomena (CEIDP), Boulder, New Mexico, USA, pp. 294-297, October , 2004

[11] B. R. Varlow, D. W. Auckland, "The influence of mechanical factors on electrical treeing", IEEE Transactions on Dielectrics and Electrical Insulation, Vol. 5, No. 5, pp. 761-766, 1998

[12] R. Vogelsang, R. Brutsch, K. Froehlich, "How imperfections in mica tape barriers influence tree growth and breakdown time", Annual Report Conference on Electrical Insulation and Dielectric Phenomena (CEIDP), Albuquerque, USA, pp. 657-660, October, 2003

[13] L. Niemeyer, L. Pietronero, H. J. Wiesmann, "Fractal dimension of dielectric breakdown”, Physical Review Letters, Vol. 52, pp. 1033-1036, 1984

[14] H. J. Wiesmann, H. R. Zeller, "A fractal model of dielectric breakdown and prebrakdown in solid dielectrics", Journal of Applied Physics, Vol. 60, pp. 1770-1773, 1986

[15] L. A. Dissado, P. J. J. Sweeny, "Physical model for breakdown structures in solid dielectrics", Physical Review, Vol. B 48, pp. 1226112268,1993

[16] J. C. Fothrgill, L. A. Dissado, P. J. J. Sweeny, "A discharge avalanche theory for the propagation of electrical trees", IEEE Transactions on Dielectrics and Electrical Insulation, Vol. 1, No. 3, pp. 474-486, 1994

[17] M. D. Noskov, A. S. Malinovski, M. Sack, A. J. Schwab, "Selfconsistent modeling of electrical tree propagation and PD activity", IEEE Transactions on Dielectrics and Electrical Insulation, Vol. 7, No. 6, pp. 725-733, 2000

[18] M. G. Danikas, I. Karafyllidis, A. Thanailakis, A. M. Bruning, "Simulation of electrical tree growth in solid dielectrics containing voids of arbitrary shape", Modelling and Simulation in Materials Science and Engineering, vol. 4, pp. 535-552, 1996.

[19] I. Karafyllidis, M. G. Danikas, A. Thanailakis, A. M. Bruning, "Simulation of electrical tree growth in solid insulating materials", Archiv fuer Elektrotechnik, Vol. 81, pp. 183-192, 1998

[20] G. E. Vardakis, M. G. Danikas, I. Karafyllidis, "Simulation of space charge effects in electrical tree propagation using Cellular Automata", Materials Letters, Vol. 56, pp. 404-409, 2002

[21] G. E. Vardakis, M. G. Danikas, "Simulation of tree propagation in polyethylene including air void by using Cellular Automata: The effect of space charges", Archiv fuer Elektrotechnik, Vol. 84, pp. 211-216, 2002

[22] G. E. Vardakis, M. G. Danikas, "Simulation of electrical tree propagation using Cellular Automata: The case of conducting particle included in a dielectric in point-plane electrode arrangement", Journal of Electrostatics, Vol. 63, pp. 129-142, 2005

[23] G. E. Vardakis, M. G. Danikas, "Simulation of electrical tree propagation in a solid insulating material containing spherical insulating particle of a different permittivity with the aid of Cellular Automata", Facta Universitatis, Vol. 17, pp. 377-389, 2004
[24] J. von Neumann, Theory of self-reproducing automata, University of Illinois, Urbana, 1966

[25] B. Chopard, M. Droz, Cellular Automata modeling of physical systems, Cambridge University Press, 1998

[26] G. E. Vardakis, Breakdown phenomena in solid insulating materials: A study of electrical tree propagation, Ph. D. Thesis, Democritus University of Thrace, Department of Electrical and Computer Engineering, Xanthi, Greece, 2006 (in Greek)

[27] M. G. Danikas, A. D. Karlis, "Some observations on the dielectric breakdown and the importance of cavities in insulating materials used for cables and electrical machines", Advances in Electrical and Computer Engineering, Vol. 11, No. 2, pp. 123-126, 2011

[28] A. Kelen, M. G. Danikas, "Evidence and presumption in PD diagnostics", IEEE Transactions on Dielectrics and Electrical Insulation, Vol. 2, No. 5, pp. 780-795, 1995

[29] A. Kelen, "Studies on partial discharges on solid dielectrics: A contribution to the discharge resistance testing of insulating materials", Acta Polytechnica Scandinavica, No. EI 16, pp. 138, 1967

[30] M. S. Naidu, V. Kamaraju, High voltage engineering, $2^{\text {nd }}$ edition, Eds. Tata McGraw-Hill Publishing Co. Ltd., New Delhi, India, 2000 